\title{
Detection of Dirofilaria immitis antigen in cats in Mosul city
}

\author{
W.A. Ahmed ${ }^{1}$, Z.D. Mohammed Zaki ${ }^{2}$ and M.H. Hasan $^{1}{ }^{\odot}$ \\ ${ }^{1}$ Department of Microbiology, College of Veterinary Medicine, University of Mosul, ${ }^{2}$ Department of Dentistry, Al-Noor \\ University College, Mosul, Iraq
}

\begin{tabular}{l} 
Article information \\
\hline Article history: \\
Received November 22, 2020 \\
Accepted February 27, 2021 \\
Available online October 28, 2021 \\
\hline Keywords: \\
Dirofeleria imitis \\
Cats \\
Direct ELISA \\
Mosul \\
\\
\hline Correspondence: \\
W.A. Ahmed \\
wasenamjad@ yahoo.com
\end{tabular}

\begin{abstract}
This study is the $1^{\text {st }}$ trial to detect of Dirofeleria imitis in cats in Mosul city, Iraq, Dirofilariasis is the most dangerous nematodes which infect cats, through this study blood samples was collected from 200 cats (different ages, source and rearing management) to investigate from the mature female worms of $D$. immitis by using direct ELISA, results showed total percentage of infection was 7\% (14/200 animals), the relationship between the infection with age of cats was proportional to the age of cats, as the percentage increases with the age of cats, the high prevalence of infection was recorded in cats more than 2 years old $4 \%$, the kittens less than 1 year old showed low prevalence of infection $0.5 \%$, statistically there is a significant differences between the oldest animals with other ages, significant differences between outdoor cats which recorded high prevalence of infection 4\%, while Indoor animals recorded low prevalence of infection $3 \%$ with $D$. imitis, 10 of imported cat was infected with D. imitis with high prevalence of infection $5 \%$ when compare with native cats $2 \%$, without significant differences between two groups, this study was conducted that the prevalence of $D$. imitis is high in adult cats, with high prevalence in outdoor rearing and the cats with imported origin.
\end{abstract}

DOI: 10.33899/ijvs.2021.128997.1616, (CAuthors, 2022, College of Veterinary Medicine, University of Mosul.

This is an open access article under the CC BY 4.0 license (http://creativecommons.org/licenses/by/4.0/).

\section{Introduction}

Several parasitic diseases affect cats $(1,2)$ and the Dirofilariasis is the disease caused by nematode Dirofilaria immitis known as the heartworm because the site of the worms in the lungs arteries (right ventricle) (3), the disease distributed worldwide and affected both feline and canine species (4). Animals can be infected via female mosquito which can be faded to blood of infected animals, L3 can be developed from microfilariae in feline only (5). Vector adequacy effect of larval development of the mosquito individual (6). Then larvae transcend through the pharynx then gut which stay approximately 1 day (7). They then migrate to the Malpighian tubules and invade the cells then transformation to the so sausage stage L1 mute to the L2 stage then to L3 (8). L3 emerges from the folded labium and rests on the skin of the host immersed in a drop of haemolymph then enters the host (9). Culex and Anopheles is the main vectors of transmission of the disease the clinical signs of infected cats manifested as chronic (subclinical) or acute death form and mainly limited to respiratory signs and the disease called Heart Worm Associated Respiratory Disease (HARD) (10). The direct ELISA, is a perfect test to investigate protein of female worm's genital tract the number of female heartworms in cats is so low of infection with male worms which high (11). Negative antigen test result in infected animals can caused by two reasons: immaturity female worms or decrease numbers of female worms, while false-positive results is low, so the antigen test is considered to screening test for heartworm infection in cats (12). Detection of $D$. immitis is attempt by using serological assays, thorax $\mathrm{X}$ ray, and echo-cardiogram, microfilaria is present in circulating 6 months' post infection, the serological assays are sensitive about $97 \%$, they are considered to have good sensitivity, Therefore, the most effective methods for 
diagnosis are chest X-ray, echo-cardiogram, and serological assays (13). Because there is no study which include the $D$. imitis in cats in Iraq, this study was aimed to detection of feline $D$. immitis antigens in cats using direct-ELISA.

\section{Materials and methods}

\section{Animals}

Two hundred of house hold and stray cats was examined. The age range of the cats was between 1 and 9 years old, estimated by the teeth, different source, rearing management.

\section{Blood collections}

A blood sample $2 \mathrm{ml}$ was collected from cephalic vein of cat after sedation by the intramuscular injection of ketamine $7.5 \mathrm{mg} / \mathrm{kg}$. The collected blood was added in to tube without anticoagulant (11). Serum was separated from clotted blood in a non-additive tube (14).

\section{Direct ELISA}

Antigen from the mature female worms of $D$. immitis was detected by using an ELISA kit (DiroCHEK $\AA$, SYNBIOTICS Corporation, San Diego, CA 92127, USA). The ELISA procedures was attempt according the manufacturer's manual.

\section{Statistical analysis}

The difference in the percentages of infection between the various clinical status and ages of cows were assessed by using two-sided Chi-square test in IBM-SPSS statistics version19 program (15).

\section{Results}

Table 1 recoded the prevalence of $D$. imitis antigen in cats with different age, the relationship between the infection with age of cats was proportional to the age of cats, as the percentage increases with the age of cats, the high prevalence of infection was recorded in cats more than 2 years old, the kittens less than 1-year-old showed low prevalence of infection, statically there is a significant difference between the oldest animals with other ages in significantly different (Table 1).

Outdoor cats recorded high prevalence of infection, while Indoor animals recorded low prevalence of infection with $D$. imitis with significant differences between it, in significantly different (Table 2).

Ten of imported cat was infected with $D$. imitis with high prevalence of infection when compare with native cats, without significant differences between two groups (Table 3).

Table 1: The relationship between the infection of $D$. imitis and age of cats

\begin{tabular}{lcccc}
\hline Age & No. of cat examined & No. of positive $(\%)$ & $(\%)$ No. of Negative & P- Value \\
\hline Less than 1 year & 67 & $1(0.5)^{\mathbf{a}}$ & $66(33)$ & 0.07 \\
$\leq 1$ year- $\geq 2$ years & 61 & $5(2.5)^{\mathbf{a}, \mathbf{b}}$ & $56(28)$ & 0.5 \\
$\leq 2$ years & 72 & $8(4)^{\mathbf{b}}$ & $64(32)$ & 0.02 \\
\hline Total & 200 & $14(7)$ & $186(93)$ & \\
\hline
\end{tabular}

Values significantly different at $\mathrm{P}<0.05$ between cats different ages are labeled with the vertically different letters a, $\mathrm{b}$, c.

Table 2: the relationship of percentage of infection of $D$. imitis with rearing condition of cats

\begin{tabular}{lcccc}
\hline Rearing condition & No. of cat examined & No. of positive $(\%)$ & $(\%)$ No. of Negative & P- Value \\
\hline House hold(Indoor) & 154 & $6(3)^{\mathbf{a}}$ & $148(74)$ & 0.001 \\
stray (outdoor) & 46 & $8(4)^{\mathbf{b}}$ & $38(19)$ & \\
\hline Total & 200 & $14(7)$ & $186(93)$ & \\
\hline
\end{tabular}

Values significantly different at $\mathrm{P}<0.05$ between cats different ages are labeled with the vertically different letters a, $b$, c.

Table 3: The prevalence of infection of $D$. imitis in Native and imported cats

\begin{tabular}{lcccc}
\hline Source & No. of cat examined & No. of positive $(\%)$ & $(\%)$ No. of Negative & P-Value \\
\hline Imported & 111 & $10(5)^{\mathrm{a}}$ & $101(50.5)$ & 0.2 \\
Native & 89 & $4(2)^{\mathrm{a}}$ & $85(42.5)$ & \\
\hline Total & 200 & $14(7)$ & $186(93)$ & \\
\hline Values significantly different at $\mathrm{P}<0.05$ between cats different ages are labeled with the vertically different letters a, b, c.
\end{tabular}




\section{Discussion}

D. imitis is wide spread infected parasite in cats, the parasite is not reported in cats in Iraq, so this study was reported total percentage of infection (7\%), this percentage is so low, the reason of that may due to several causes spontaneous elimination of parasite, sudden death of animals, and the detection of microfilieria in peripheral blood is un satisfactory and microifileria is rarely found (16). The results of the present study showed first occurrence of D. imitis in cats in Mosul city.

Several species of culicid act as vectors and play important role in $D$. imitis infection (17). Direct ELISA test give a positive result which indicated active adult worm infection and this result is highly specific, while the sensitivity is decrease when female worm two or fewer $(18,19)$. The study conducted that the antibodies only indicate that an infection occurred and does not provide a guarantee that it still exists. There are variance results of the relationship between $D$. imitis infection and age of animals $(20,21)$. The infection of $D$. imitis increase with increase of age because increase of duration of exposure to infection (vectors) (22). The results Showed the infection in all age of animals and revealed the relationship of infection which affected according to health status, immune status and other infectious agents (23). Other reason is the longtime of duration of prepatent period of the D. imitis is 5-6 months (24). The results recorded differences between indoor and outdoor animals, other researchers approve this result of infection with $D$. immitis in dogs (25). The outdoors animals may increase the chance to exposure of vectors may be bearing infective L 3 of $D$. imitis and live under bad conditions, those animals may have exposed to other infectious agents which may play important role in immunosuppression of outdoor animals (26), indoor animals or house hold animals Puddles a veterinary important care and owners care this decrease the chance of infection and live under quarantine condition this decrease exposed to vectors (24). Animals which imported from different countries reported high prevalence of infection when compare with native animals (27). D. immitis has been reported in some neighborhood countries otherwise countries from which animals are imported, Saudi Arabia (28), Romania (3), Iran (29), Russia (30), Croatia, Syria, Lebanon and Turkey (31), Egypt and Qatar (32), these researchers improve the importation of infected animals to transmission the infection from country to other country as emerging disease.

\section{Conclusions}

D. imitis was first investigated in cats in Mosul city, with a higher infection in <2years old, imported, and stray cats.

\section{Acknowledgment}

The authors wish to thank the College of Veterinary Medicine, University of Mosul for financially supporting this work, laboratory of the veterinary teaching hospital, for their support and the animal's owners for their cooperation

\section{Conflict of interest}

Author declare no conflict of interests of the manuscript.

\section{References}

1. Tridiganita S. Aloe vera and Virgin Coconut Oil (VCO) accelerate healing process in domestic cat (Felis domesticus) suffering from scabies. Iraqi J Vet Sci. 2021;35(4):699-704. DOI: 10.33899/ijvs.2020.127884.1539

2. Wasan AA, Qaes TA, Sadam DH. Detection of Trichomoniasis in cattle in Nineveh province. Iraqi J Vet Sci. 2021;35(2):287-290. DOI: 10.33899/ijvs.2020.126790.1380

3. Pana D, Radulescu A, Mitrea IL, Ionita M. First report on clinical feline heartworm (Dirofilaria immitis) infection in Romania. Helminthol. 2020;57(1):49-56. DOI: 10.2478/helm-2020-0009

4. Pereira BB, Bastos BF, Keidel L, Leles D, Brener B. Feline heartworm (Dirofilaria immitis) infection: First case report of serological diagnosis in Brazil, confirmed by molecular assay. Anais da Academia Brasileira de Ciencias. 2018;90(2):93-97. DOI: 10.1590/0001-3765201820170063

5. Tahir D, Davoust B, Parola P. Vector-borne nematode diseases in pets and humans in the Mediterranean basin: An update. Vet World. 2019;12(10):1630-43. DOI: 10.14202/vetworld.2019.1630-1643

6. Khodabakhsh M, Malmasi A, Mohebali M, Zarei Z, Kia EB, Azarm A. Feline Dirofilariosis due to Dirofilaria immitis in Meshkin Shahr district, Northwestern Iran. Iran J Parasitol. 2016;11(2):269-273. [available at]

7. Velasquez L, Blagburn BL, Duncan DR, Johnson EM, Allen KE, Meinkoth J. Increased prevalence of Dirofilaria immitis antigen in canine samples after heat treatment. Vet Parasitol. 2014;206(1-2):6770. DOI: $10.1016 /$ j.vetpar.2014.03.021

8. Rahmat S, Seyed MS, Mehdi M, Zabihollah Z, Majid G, Abbasali R. Development of new recombinant $\mathrm{DgK}$ antigen for diagnosis of Dirofilaria immitis infections in dogs using ELISA technique and its comparison to molecular methods. Iran Biomed J. 2018;22(4):283289. DOI: $10.22034 / \mathrm{ibj} .22 .4 .283$

9. Alexandre CO, Grazielle SR, Priscila AF, Flavya MA, Norma L. Unusual feline Dirofilaria immitis infection: A case report. Rev Bras Parasitol. 2020;29(3):1-5. DOI: 10.1590/s1984-29612020061

10. John KG. The serologic diagnosis of heartworm infection in dogs and cats. Clin Tech Small Anim Pract. 1998;13(2):83-87. DOI: 10.1016/S1096-2867(98)80011-X

11. Ray D, Bryon L, Blagburn MT, William B, Betsy W, Calvin J, Russell $\mathrm{C}$, Pat R, Sharron B. The progression of heartworm associated respiratory disease (HARD) in SPF cats 18 months after Dirofilaria immitis infection. Parasit Vect. 2017;10(2):53-537. DOI: 10.1186/s13071-017-2425-9

12. Matsumura K, Kazuta R, Endo K, Tanaka TI. The enzyme-linked immunosorbent assay for detecting antibodies against Dirofilaria immitis in dogs. Vet Parasitol. 1986;21(3):165-171. DOI: 10.1016/0304-4017(86)90063-4

13. Glenn R, Frank RR, Mondesire KS, Brandt S, Nancy W. Antibody to the Dirofilaria immitis aspartyl protease inhibitor homologue is a diagnostic marker for feline heartworm infections. J Parasitol. 1998;84(6):1231-1236. DOI: $\underline{10.2307 / 3284679}$ 
14. Wasan AA. The serological diagnosis of canine Leishmaniasis by using ELISA in Nineveh province. Iraqi J Vet Sci. 2019;33(2): 111114. DOI: $10.33899 /$ ijvs.2019.163194

15. Leech NL, Barrett KC, Morgan GA. SPSS for Intermediate Statistics: Use and Interpretation. USA: Lawrence Erlbaum Asso; 2007.

16. Vieira L, Silvestre F, Fontes AP, Balreira AC. Seroprevalence of heartworm (Dirofilaria immitis) in feline and canine hosts from central and northern Portugal. J Helminthol. 2015;89(5):625-629. DOI: $10.1017 /$ S0022149X14000352

17. Walter T. Clinical aspects of dermatitis associated with Dirofilaria repens in pets: A Review of 100 canine and 31 feline cases (19902010) and a report of a new clinic case imported from Italy to Dubai. J Parasitol Res. 2011;12(1):90-98. DOI: 10.1155/2011/578385

18. Alahmed A, Al-Kuriji MA, Kheir SM, Alahmedi SA, Hattabi MA, AlGashmari MM. Mosquito fauna and seasonal activity in Makka Al Mukarrama Region, Saudi Arabia. J Egypt Soc Parasitol. 2009;39:991-1013. DOI: 10.1016/j.jksus.2010.12.001

19. Al-Khreji AM. Survey and distribution of mosquito species (Diptera culicidae) and description of its habitat in Riyadh district, Kingdom of Saudi Arabia [master's thesis]. Riyadh: King Saud University Riyadh; 2005. [available at]

20. McCall JW, Genchi C, Kramer LH, Guerrero J, Venco L. Heartworm disease in animals and humans. Advan Parasitol. 2008;66:193-285. DOI: $10.1016 / \mathrm{S} 0065-308 \mathrm{X}(08) 00204-2$

21. Cardoso L, Lopes AP, Sherry K, Schallig H, Solano GL. Low seroprevalence of Leishmania infantum infection in cats from northern Portugal based on DAT and ELISA. Vet Parasitol. 2010;174:37-42. DOI: 10.1016/j.vetpar.2010.08.022

22. Song KH, Lee SE, Hayasaki M, Shiramizu K, Kim DH, Cho KW. Seroprevalence of canine dirofilariosis in South Korea. Vet Parasitol. 2003;114:231-236. DOI: 10.1016/s0304-4017(03)00137-7

23. Fan CK, Su KE, Lin YO, Lin YH, Liao CW, Du WY, Chiou HY. Seroepidemiologic survey of Dirofilaria immitis infection among domestic dogs in Taipei city and mountain aboriginal districts in Taiwan (1998 -1999). Vet Parasitol. 2001;102:113-120. DOI: 10.1016/s0304-4017(01)00511-8

24. Rhee JK, Yang SS, Kim HC. Periodicity exhibited by Dirofilaria immitis microfilariae identified in dogs of Korea. Korean J Parasitol. 1998;36:235-239. DOI: 10.3347/kjp.1998.36.4.235

25. Martin TE, Collins GH. Prevalence of Dirofilaria immitis and Dipetalonema reconditum in Greyhounds. Australian Vet J. 1985;62:159-163. DOI: $10.1111 /$ j.1751-0813.1985.tb07278.x

26. Pantchev N, Schaper R, Limousin S, Norden N, Weise M, Lorentzen L. Occurrence of Dirofilaria immitis and tick-borne infections caused by Anaplasma phagocytophilum, Borrelia burgdorferi sensu lato and Ehrlichia canis in domestic dogs in France: Results of a countrywide serologic survey. Parasitol Res. 2009;105:101-114. DOI: 10.1007/s00436-009-1501-2

27. Yildirim A, Ica A, Atalay O, Duzlu OA. Prevalence and epidemiological aspects of Dirofilaria immitis in dogs from Kayseri province, Turkey Res Vet Sci. 2007;82:358-863. DOI: 10.1016/j.rvsc.2006.08.006

28. Yaman M, Guzel M, Koltas IS, Demirkazik M, Aktas H. Prevalence of Dirofilaria immitis in dogs from the Hatay province, Turkey. J Helminthol. 2009;83:255-260. DOI: 10.1017/S0022149X08198832

29. Omar IO, Elgailani A, Elamin SA, Omer AN. Serorevalence of Dirofilaria immitis in dogs and cats in Riyadh City, Saudi Arabia. Trop Biomed. 2018,35(2):531-540. [available at]

30. Tatiana TV, Svetlana Y, Alexandru T, Heidrun T, Renke L, Egbert T. Detection of Dirofilaria repens and Dirofilaria immitis DNA in mosquitoes from Belarus. Parasitol Res. 2016;3(2):122-114. DOI: 10.1007/s00436-016-5118-y

31. Rodrigo ME, Carreton J, Gonzalez M, Mellado H. Heartworm disease (Dirofilaria immitis) and their vectors in Europe - new distribution trends. Front Physiol. 2012;196(3):1-11. DOI: 10.3389/.2012.00196

32. Natascia R, Tarello W. Probably imported canine heartworm in Qatar. Priory Med J. 2011;34(1):20-23. [available at]

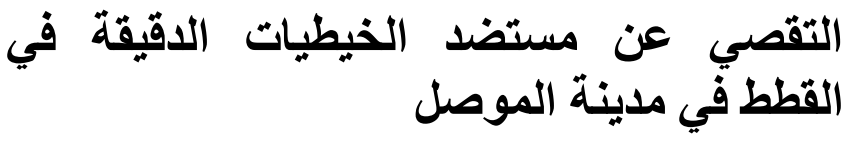

$$
\begin{aligned}
& \text { وسن أمجد احمد' زينة ضبيان محمد زكي' و منال حمادي حسن' }
\end{aligned}
$$

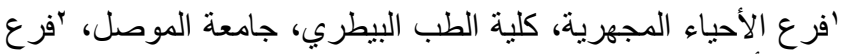

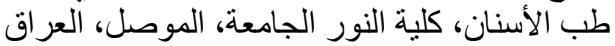

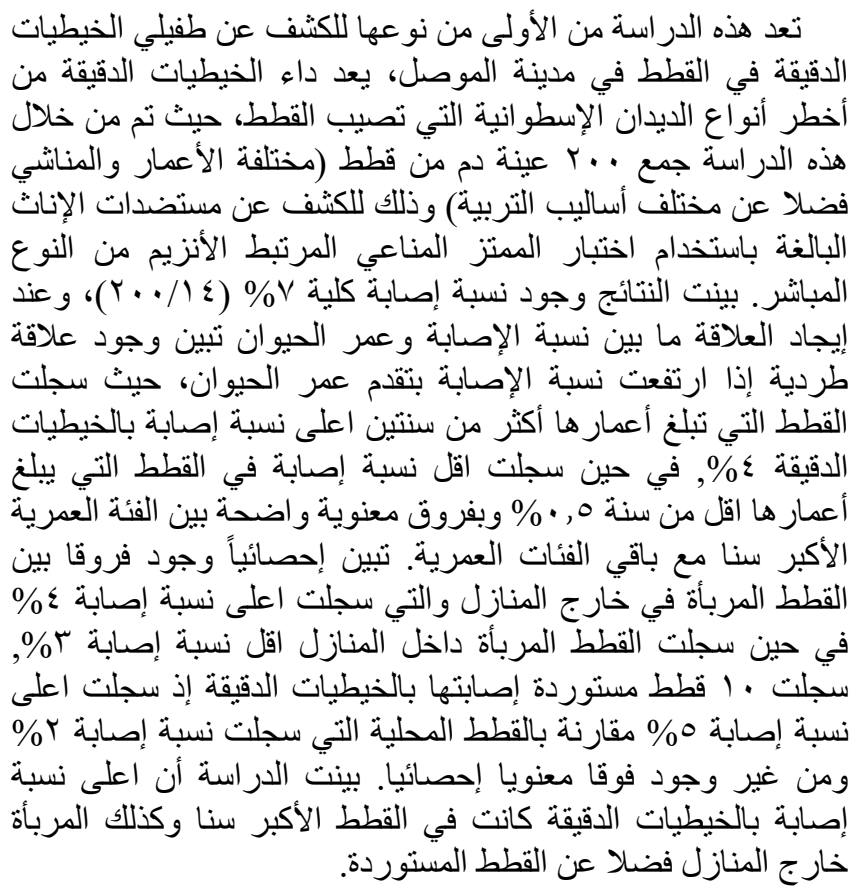

